\title{
FONTES DO DIREITO ADMINISTRATIVO
}

\author{
Temístocles Brandão Cavalcânti \\ Procurador Regional da República no Distrito Federal
}

SUMARIO : Fontes gerais e fontes especiais - Classiticação das fontes - Doutrina - Jurisprudência - Castume - A lei.

O problema das fontes do direito em geral e das diversas disciplinas jurídicas, em particular, sempre constituiu assunto de graves controvérsias, quer sob o ponto de vista filosófico, quer sob o seu aspecto técnico, como elemento a ser aproveitado na constituição da norma jurídica e na formação do direito.

A participação dos fenômenos humanos na elaboração e no desenvolvimento do direito é que seria, então, considerada como expressão mais lata, mais extensa do problema das fontes.

DU PASQUIER ${ }^{1}$ observa que a palavra fontes sugere uma metáfora, qual seja a analogia das fontes do direito com as fontes de um rio, lugar de onde nasce, origem. Exemplificando - a fonte do serviço militar obrigatório está na Constituição Federal.

Preferimos, entretanto, aqui considerar as fontes como os elementos que contribuem para a formaçao e desenvolvimento do direito.

O material a ser empregado poderá ser jurídico ou estranho à ciência do direito, ciências complementares, de que se socorrem necessàriamente os juristas e os legisladores para a formação do direito.

Fontes gerais e fontes especiais : - As fontes podem ser gerais ou especiais, as gerais têm mais um cunho filosófico, as outras atuam mais diretamente na sua formação, com elas é que o legislador e o juiz dão forma e aplicação ao direito, segundo a observação de GeNY.

No caso especial do direito administrativo, o material pode ser encontrado não sòmente nas ciências sociais e políticas, mas tam-

1 Introduction à la theorie générale et à la philosophio du droit, $\mathrm{a}^{\circ} 52$. 
bém nos conhecimentos técnicos, que são os instrumentos da ciência administrativa.

A. MERKL divide as fontes do direito administrativo em eventuais e específicas. Nas primeiras, devem-se incluir as manifestações jurídicas que possivelmente contêm direito administrativo, enquanto as segundas são aquelas especializadas cujo conteúdo é essencialmente administrativo.

A observação é exata especialmente no caso do direito administrativo, que é um ramo derivado do direito público, inicialmente influenciado até pelo civilismo, de que se vai emancipando aos poucos, a golpes quase que de fôrça.

As fontes do direito administrativo, ainda as mais imediatas, acham-se por aí semeadas até no Código Civil, que ainda contém alguns princípios fundamentais do direito administrativo.

Assim, a classificação dos bens públicos, o princípio da responsabilidade do Estado (teoria subjetiva) etc., são matérias contidas em nossa codificação civil.

O mesmo ocorre em nossa legislação processual, na organização judiciária, na legislação sôbre águas, minas, caça, pesca, florestas, legislação mista, civil, administrativa, e mesmo penal, onde se encontra farto material para a construção do direito administrativo.

A ciência do Estado, o chamado direito político ou constitucional constituem também as fontes imediatas, diretas do. direito administrativo.

Classificação das fontes : - A classificação das fontes do direito administrativo obedece, mais ou menos, ao mesmo critério para a das outras disciplinas jurídicas, especialmente do direito público constitucional.

Assim, alguns incluem as costumeiras, racionais, positivas e doutrinais, reduzindo, entretanto, autores como DEL VECCHIO, a duas apenas - a lei e os costumes, ou ainda, como querem outros, a lei, os costumes e a consciência jurídica (CLóvis BEviláquA).

$O$ professor LÉoN Duguir insurge-se contra essas classificações em geral, considerando o costume, a jurisprudência e a lei como simples modos de constatação da regra do direito. ${ }^{2}$

Como veremos adiante, não deixa de ter razão o eminente professor de Bordéus, embora a norma legal muitas vêzes apenas venha dar fôrça obrigatória, coercitiva, a uma situação de fato, já preestabelecida.

A lei é fonte geradora de direitos, embora, na observação de Clóvis Beviláqua, tenha muito de arbítrio e, em pouco tempo, perca o texto legal a sua significação e oportunidade em relação à vida social, sempre em evolução e transformação.

2 Traite de Droit Constitutionnel, I, pág. 154. 
$\mathrm{Na}$ expressão lei, devemos compreender tôda a escala das normas, na sua hierarquia, desde a Constituição até as mais elementares, que completam, em ambientes e raios de ação cada vez mais restritos, as normas jurídicas da mais alta hierarquia.

Assim as leis, os regulamentos, os regimentos, as portarias, as circulares, as instruções etc.

Todo êsse conjunto de manifestações do direito, obra do arbítrio, da imaginação, da técnica e especialmente da vontade do homem ${ }^{3}$, deve constituir fontes do direito administrativo, porque são manifestações do poder do Estado e formas disciplinadoras das atividades humanas, tornadas obrigatórias.

Em nosso direito, vamos encontrar diversas modalidades de normas, quer no direito anterior, principalmente sob o regime imperial e da colonização, quer no regime republicano.

Assim, os alvarás, as provisões reais, os regimentos, os estatutos, os forais, as cartas régias, as resoluções de consulta, as provisões, os assentos, os avisos, as portarias, as instruções, as ordens etc.

Doutrina: - A doutrina é outra fonte, e esta se manifesta através da opinião dos doutos, dos escritores, dos que estudaram o direito e comentaram as leis.

A communio opinio doctorum, o direito constituído pela opinião dos peritos (jus prudentium), tem tido uma considerável importância. Já não falamos no direito romano, no Digesto, nem na influência dos glosadores, mas a própria autonomia do direito administrativo, a sua emancipação do direito constitucional e do direito civil é obra da doutrina.

Observa Charles Beard, em seu livro Public Policy and general Welfare, que os primeiros livros sôbre administração foram escritos pelos juristas, tanto na América como na Europa.

"The first work on Werwaltung in germany were on Verwaltunrecht, the law of administration. When the school of Political Science was founded at Columbia University, the leaders in the study of government were men trained in law. The first great American work on public administration was Professor FraNk G. GoodNow's Comparative Administrative Law. Law was the beginning ifninot the end of administration".

Antecedeu, assim, o trabalho doutrinário à construção não só do direito administrativo mas ainda da própria ciência da administração.

3 Ver F. GENy, Science et Technique en droit privé positif, vol. III, pág. 85. 
Jurisprudência : - Tanto quanto a própria lei, a jurisprudência serve de fonte ao direito administrativo, porque as decisões e arestos judiciais, com fôrça obrigatória, têm a mesma expressão jurídica da lei.

Ainda mais, aos tribunais é dado declarar o próprio sentido da lei, por meio da interpretação. Nos países como a Inglaterra, onde a construção do direito cabe em grande parte aos tribunais (judge made laws), ou mesmo naqueles onde existem instâncias administrativas, especializadas, verifica-se influência ainda maior da jurisprudência, que contribuiu decisivamente para isolar o direito administrativo do direito privado, se mais não fôra, ao menos pela natureza específica dos tribunais administrativos, de sua composição, do seu critério de julgamento.

A influência da jurisprudência é tão preponderante que o direito administrativo já foi classificado como verdadeiro common law, corpo de case-law, judge-made law, na expressão de DICEY, * sustentando, aliás, ponto de vista extremado contra a sua codificação.

BIElsa chega até a admitir a jurisprudência no contencioso administrativo, como fonte criadora do direito administrativo, função pretoriana, porque aquelas instâncias julgadoras penetram ainda no mérito das controvérsias, acima, portanto, da mera apreciação da legalidade dos atos administrativos.)

Costume: - Se a lei constitui a norma de direito inflexível, rígida, o costume representa um conjunto de regras jurídicas consolidadas no consenso do povo e na consciência coletiva.

Há um largo debate em tôrno da natureza do costume e do seu valor como elemento constitutivo do direito, bem como da obrigatoriedade de seus princípios.

Para Windscheid ${ }^{5}$, por direito costumeiro entende-se aquêle direito que vem sendo usado de fato, sem que o Estado o haja consagrado. A sua fôrça obrigatória decorre da conviçcão, de quem o pratica, de que está realmente aplicando o direito.

Uma regra aplicada diuturnamente é considerada por todos como obrigatória, sancionada pela conivência de todos; é o que se pode ter como costume, na definição de BIANCHI. ${ }^{8}$

4 Droit Const., pág. 462. Ver Sir CECh TH. CARR, Concerning English Adminiotrative Law; James Landes, The Administrative Process.

5 Diritto dello Pandette, trad. Fadda e Bensa, vol. I, § 15.

6 F. Bianchr, Principin generale sulle legge, pág. 102; Pasqualle Fiore, II Diritto Civile Italiano, vol. I, pág. 91. 
A lei de 18 de agôsto de 1769 (lei da boa razão) procurou definir o direito costumeiro, estabelecendo as condições em que deveria ser tido como direito, condições assim enumeradas:

a) conformidade com a boa razão, que deve constituir o espírito das leis;

b) não ser contrária a lei alguma;

c) ter mais de cem anos.

Seria longa a crítica dessas disposições, que valem como a definição legal, no nosso direito anterior, do que se deva entender por direito costumeiro.

O direito costumeiro tem uma expressão primitiva. $O$ seu interêsse foi desaparecendo por fatos diversos. A vida social foi-se tornando mais complexa. O desenvolvimento dos conhecimentos humanos, a diferenciação das funções sociais, exigem formas mais rígidas de disciplina social. $O$ aperfeiçoamento do saber hamano, especialmente, criou a técnica do direito, a especialização científica e o aparecimento dos juristas. Veio a legislação positiva.?

A transformação do direito, desde a antiguidade até a idade moderna, é uma escala ascendente de racicnalização e sistematização jurídica.

E tal, porém, a importância do direito costumeiro, que ainda hoje $i$ o mesmo trazido a debate, tôda vez que se trata de estudar as fontes $:$ - direito positivo. ${ }^{\$} \mathrm{E}$ êsse estudo leva sempre a concluir que o costumc 'eve ser considerado como fonte do direito positivo, zorque, na maioria das vêzes, o legislador nada mais fêz do que cunsagrá-lo como direito objetivo.

Daí a teoria de que a lei é, apenas, o reconhecimento de uma situação de fato, já anteriormente existente na consciência popular, firmada pelo costume. ${ }^{\circ}$

No direito romano ${ }^{10}$, no direito medieval ${ }^{11}$, o costume como norma jurídica obrigatória constituía doutrina predominante. E preciso, porém, reconhecer que o direito moderno vai cada vez mais fortalecendo o valor da lei como fonte do direito, embora modificando a técnica legal, por uma flexibilidade mais acentuada das suas normas.

7 Ribas, Direito Civil vol. I, pág. 139; Cândido MEndes, Código Filipino, página 476; Clóvis BevilAqua, Teoria Geral do Direito Givil, pág. 476.

8 Dignos de menção, pelo seu valor, são os estudos de Puchra e Savigny a respeito do direito costumeiro e a sua predominância sôbre a lei. Ver Savigry, Traité de Droit Romain.

9 Deve-se referir especialmente, aqui, o excelente capitulo sôbre direito costumeiro que se encontra em EDUARDo Espinola, Sistema de Direito Civil Brasileiro, vol. I, págs. 99 e seguintes. Igualmente, Sclaloja, Dizionario di Diritto Privato, verbum Conoutudine

10 G. Padeletri, Storia del diritto romano.

11 Eschrach, Introduction fénérale à l'Etude du droit. 
Este fenômeno é de alto interêsse, porque importa na multiplicidade e na diferenciação do sentido da norma legal.

$O$ valor do costume na formação do direito administrativo, como observa MERKL, é grande apenas como elemento de investigação das fontes jurídico-administrativas. Neste terreno, é realmente importante a constituição dos costumes e usos.

Como ensina ORLANDo, ${ }^{12}$ porém, não é possível deixar de reconhecer a importância de fatôres e tendências sociais oriundas do costume ou que produzem efeitos análogos aos do costume pròpriamente dito.

OTTO MAYER ${ }^{13}$ faz a crítica dos que atribuem importância aos costumes como fonte do direito administrativo e mostra como é restrita a sua aplicação. O Estado moderno e o funcionamento das instituições políticas e administrativas baseiam-se em normas jurídicas uniformes que devem ser obrigatòriamente aplicadas pela administração. $\mathrm{Na}$ falta do direito positivo, não the é lícito aplicar disposições costumeiras, que não podem constituir fonte geradora de direitos.

Os costumes podem, entretanto, ser tidos como fonte geradora da lei; esta pode consagrar como direito os usos e costumes integrados na vontade e na consciência coletiva.

Ocorre, porém, muitas vêzes, que a lei manda socorrer-se dos usos e costumes do lugar, dando assim maior elasticidade e relatividade à sua aplicação. Pode-se citar, como exemplo, o que dispõe o Código Civil, art. 588, $\S 2 .^{\circ}$, quando se refere à divisão de tapumes $e$ às normas de direito administrativo a serem usadas pelas posturas municipais. Igualmente, 0 art. 1.012 do Código Civil manda respeitar os costumes locais na determinação do prazo da locação.

As praxes administrativas e a jurisprudência são subtipos, como ensina MERK, do costume. ${ }^{14}$

A praxe decorre da aplicação diuturna das leis e regulamentos pela administração, que vai fornecendo a chamada jurisprudência administrativa.

Bielsa ${ }^{15}$ distingue, também, o costume da prática burocrática. O primeiro nasce da consciência do povo, surge espontâneamente da atividade administrativa, enquanto a praxe administrativa se es-

12 Primo Trattato di Diritto Amministrativo, I, págs. 1.056 e seguintes.

13 Drait administratif allemand, I, págs. 168 e segs.

14. Teoría general, pág. 143.

15 Derecho administrativo, vol. I, pág. 29. No mesmo sentido, Santr Romano, Corso, pág. 66 . Ver também RANELETTi, $L_{a}$ consuetudine como fonte del diritto pubblico interno, in Rev. di diritto pubblico, vol. V, pág. 146. 
tende à forma de entender e de interpretar as leis e os regulamentos por parte da autoridade.

A verdade, porém, é que a praxe administrativa, como o costume, tem influência secundária na formação do direito. Valem como elemento para justificar o procedimento de autoridade na fundamentação de suas decisões.

Ali, os precedentes constituem razão de equidade, que serve de fundamento para justificar determinadas decisões.

A lei : - Dentro do nosso regime político, porém, o direito decorre da lei, que é a grande fonte geradora das situações jurídicas.

$O$ assunto permitiria longas considerações. Ficam aqui, porém, apenas algumas observações gerais sôbre um tema que merece novos estudos e investigações que pretendemos trazer oportunamente a esta Revista. 